graphs and allied instruments in use in the Observatory. He showed an early interest in the spectra of novæ, in the characteristics of sunspot spectra and in the comparison of centre and limb spectra in the Sun. His measurement of solar rotation at different levels in the solar atmosphere showed that the higher strata rotate faster and with a smaller equatorial acceleration than the lower strata. His next major contribution to astrophysics, the one for which the Gold Medal of the Royal Astronomical Society was in large part awarded in 1917, was the spectroscopic determination of stellar parallaxes. The first paper with Kohlschütter on the criteria provided by varying relative strengths of spectral lines for determination of absolute magnitudes of stars appeared in 1914. Afterwards Adams extended the work to cover a much wider range of spectral types and he published spectroscopic parallaxes of thousands of stars. His work led to a direct probing of the galaxy to far greater distances than had hitherto been pos. sible except by statistical methods.

Among much other work of his mention must be made of his analysis of high-dispersion spectra and the calibration of Rowland's scale of intensities; in novæ he noted the simple $1: 2: 3$ relations between the velocity displacements of successive outbursts : high-dispersion spectra enabled him to detect as many as five clouds of interstellar gas in the same direction in space moving with different line-of-sight velocities. Adams also both detected the white dwarf nature of the companion to Sirius and afterwards the relativity displacement to the red of the lines in its spectruma displacement of $+19 \mathrm{~km}$. $/ \mathrm{sec}$. as compared with Eddington's predicted value of $+20 \mathrm{~km}$. $/ \mathrm{sec}$. at $\lambda 4500$.

Adams was president of the Astronomical Society of the Pacific and later of the Astronomical Society of America. $\mathrm{He}$ was vice-president of the International Astronomical Union during 1935-49, keeping the Union alive during the Second World War. $\mathrm{He}$ was the senior associate of the Royal Astronomical Society, a foreign member of the Royal Society and a corresponding member of many other national academies. He was awarded the Draper Medal and the Bruce Medal in America, the Prix Janssen and the Janssen Medal in France as well as the Gold Medal of the Royal Astronomical Society. In his death the astronomical world has lost a much loved and widely revered leader.

F. J. M. Stratton

\section{Mr. P. W. Wood}

IT would seem strange to anyone in Cambridge to speak of Philip Worsley Wood in any other way than as "P. W.". His passing is a great loss to Cambridge and especially to Emmanuel College, as was that of his namesake Alex. a few years ago. Born in April 1880, he matriculated and entered Emmanuel in 1899.

'I'o one who was his exact contemporary, the passing of " $P$. W." comes as a reminder that the ranks of those who took the Mathematical Tripos Part I in the days when there was an order of merit are becoming very thin. In 1902 he was Third Wrangler, bracketed with $\mathrm{H}$. A. Webb. In 1903 he was placed in Class I, Division 2 in Part II of the Tripos, and in the next year was awarded a Smith's Prize.

"P. W." had in a high degree that facility in the solution of ingenious problems which counted for so much in the Tripos of that day. But it was not the kind of outlook for which the times were asking. With the passing of the old Tripos, mathematical fashion was for connected theory, ever widening in scope and in new points of view. Thus Wood became one of that band of teachers who held the fort for that wide range of students for whom mathematical research lay beyond their reach. As such he was an outstanding member of his College and of the Faculty. To his pupils he was devoted, meticulous and challenging. Though he retired at the age of sixty-five under the age limit, he went on teaching for the love of it until the day when he was overtaken by the illness which led to his death ten days later.

Being what he was, his original work was limited. The best known was his Cambridge Tract on "The Twisted Cubic". Not so well known was a series of papers in the London Mathematical Society Proceedings on algebraic invariants.

His activities turned early to College administration. A Fellow of Emmanuel for fifty-one years, he served for thirty-five years as lecturer in mathematics, for twenty-six years as librarian and for seventeen years as senior tutor, besides acting for some periods as vice-master. In University affairs he was not so prominent, though he was a junior proctor in 1917-18 and was for many years a much. valued member of the Local Examinations Syndicate.

As a man, "P. W." cannot be put into any class. $\mathrm{H}_{\Theta}$ was just himself-kind and appreciative but caustic and terse in conversation, diligent in all that he undertook, working hard for little reward. Having no ambition but to serve well, he lived to serve.

Some would say that his hobbies were lawn-tennis and gardening. But truly his College was his hobby and his absorbing pursuit. His home and garden were places of renewal in the companionship of his wife, his two sons and his daughter. Is it possible that he shared with them, as he did with me, in the year 1944, the discovery that that number is just $3^{5} \times 2^{3}$ ? EBENEZER CUNNINGHAM

\section{Dr. M. A. Whiteley, O.B.E.}

Martha Annie Whiteley was born on November 11,1866 , and received her early scientific training at Royal Holloway College, London, where she graduated in 1890. During the following twelve years she held appointments as science mistress at Wimbledon High School, lecturer in science at St. Gabriel's College, Camberwell, and lecturer in physical chemistry at Royal Holloway College. During the last few years of this period, from 1898, she also carried out part. time research at the Royal College of Science, and in 1902 she obtained the D.Sc. degree of the University of London (her examiners at the oral examination being Ramsay and Frankland), and in 1903 the diploma of associateship of the Royal College of Science. In the following year Tilden appointed her to be a teaching scholar on the staff of the Royal College of Science, and she was promoted assistant in 1905, demonstrator in 1908 (by which time the College had become part of the newly constituted Imperial College of Science and Technology), lecturer in 1914, and assistant professor of organic chemistry in 1920 .

Her first paper, in 1900, on "The Oxime of Mes. oxamide", set the pattern of her research activities on derivatives of malonic acid and barbituric acid. During the First World War, her specialized knowledge in this field enabled her to play an important part in the development of methods for the synthesis 